\title{
Exploration of Influencing Factors on Mechanism of Chinese Users' Continuous Trust in Transactional Virtual Community
}

\author{
Yue Huang ${ }^{1}$ \\ ${ }^{1}$ Stamford International University, Thailand \\ Correspondence: Yue Huang, Stamford International University, Thailand. E-mail: 707928@qq.com
}

Received: September 18, 2020

Accepted: September 28, 2020

Online Published: October 31, 2020

doi:10.5539/ass.v16n11p80

URL: https://doi.org/10.5539/ass.v16n11p80

\begin{abstract}
This paper studies the formation path of user trust in transactional virtual community, explores the relationship between website perception, merchant reputation and user's personal trust tendency and user's initial trust, and introduces the characteristics of internet word of mouth and sense of virtual community into the analysis framework from initial trust to continuous trust. This research used a quantitative design by developing questionnaires to collect data through the snowball sampling approach from 390 Chinese users of the well-known transactional virtual communities as research population, such as JD community, Dianping community, Tmall community, Xiaomi Forum, Dangdang - online reading community, etc. The results show that users' website perception, merchant reputation and personal trust tendency these three factors have significant positive effects on the formation of initial trust of users. And merchant reputation played the most important role in influencing initial trust of users than any two factors, followed by user's trust tendency and website perception. Besides, initial trust of users was shown to has a significant positive effect on continuous trust of users in transactional virtual community. Furthermore, the characteristics of internet word of mouth was found have significant mediation effect on initial trust and continuous trust of users. More specifically, $41.7 \%$ of the influence of the initial trust on the continuous trust was due to the internet word-of-mouth. The findings of this study provide transactional virtual community marketers and managers' valuable insights into developing effective marketing strategies to improve their community's service.
\end{abstract}

Keywords: characters of internet word of mouth, continuous trust, initial trust, merchant reputation, personal trust tendency, transactional virtual community, website perception

\section{Introduction}

According to the 45th Statistical Report on The Development of Internet in China released by China Internet Network Information Center (CNNIC), the number of Chinese netizens had reached 904 million, the number of online shopping users had reached 710 million, and the Internet penetration rate was $64.5 \%$ by the end of March, 2020 (CNNIC, 2020). The popularity of the Internet has expanded the way people trade and communicate. With the help of the Internet, many businesses have established transactional virtual communities to provide consumers with platforms for transaction information transmission, product and service purchase and exchange and interaction, so as to expand sales and increased popularity. Due to the anonymity of the community and the virtuality of the network space, consumers' perception of transactions in the community has certain risks, and their willingness to trade decreases. Therefore, establishing trust relationship has become an essential way for merchants to attract users and enhance user stickiness. In the network environment, word-of-mouth is a key factor for consumers to judge product information, and effective word-of-mouth communication positively affects consumer trust (Fan \& Miao, 2012). Trust is the antecedent of virtual community perception, which in turn could enhance trust (Zhu, Li, \& Liang, 2014). Rousseau et al. (1998) proposed that trust goes through three different stages: initial, stable and fading. Mcknight et al. (2011) believed that the establishment of initial trust was particularly important in different stages, and they pointed out that consumers' perception of website quality, perceived website risk, perceived merchant reputation and structure guarantee were the key factors to affect initial trust. Chen et al. (2008) established an initial trust model based on website features and seller reputation, and a continuous trust model based on relationship marketing and customer response, aiming at whether consumers have online shopping behaviors.

Previous studies have shown that consumers trust form is a dynamic process, however, most of the literature 
examines the influencing factors from the perspectives of initial trust and continuous trust respectively. They are less likely to explore the path of trust as a whole. Therefore, this paper, based on transactional virtual communities, studies the formation process of community users' continuous trust, discusses the characteristics of community online word-of-mouth and the mechanism of virtual community perception in the path as well as the degree of influence, and provides countermeasures and suggestions for community managers to establish user trust.

\section{Literature Review and Theoretical Framework}

\subsection{Influencing Factors of Users' Initial Trust}

\subsubsection{Website Perception}

Davis (1989) took the lead in putting forward TAM (Technology Acceptance Model), pointing out that users' use of technology is based on perception, perceived usefulness is the expected result of users' use of the technology, and perceived ease of use is the cognitive level of users' easy learning and use of the technology Koufaris et al. (2004) used TAM to verify that perceived usefulness has a positive impact on users' willingness to use. They point out that the website usefulness and ease of use will affect the trust of the user to the website. Full and comprehensive product and service information is conducive to help users make decisions, the user-friendly interface settings of the website could let users easily grasp the use of the website, which is the embodiment of the business ability. Generally, users infer from this that the merchant is capable of providing a quality product or service. Meanwhile, Gefen et al. (2003) also mention that users' perception of website usability could enhance their trust in merchants. Koufaris et al. (2004) proved that user-perceived security has a significant impact on initial trust. Inexperienced new users are more concerned about the transaction security of websites and worry about revealing personal information. These researches indicated that the initial trust of users could be increased if specific techniques are used to reduce transaction risk. As a result, user perceptions of a website's usefulness, ease of use, and security could exert an impact on initial trust. Therefore, hypothesis $\mathrm{H}_{1}$ is proposed in this study.

$\mathrm{H}_{1}$ : Website perception has a significant positive impact on initial trust of users.

\subsubsection{Merchant's Reputation}

Reputation is the reflection of merchants' behavior, reflecting whether merchants honestly provide valuable products or services to users, and it is also the basis for users to judge whether merchants are trustworthy. Jarvenpaa et al. (2000) proved through empirical research that trust is positively correlated with user-perceived merchant reputation, and good reputation contributes to the formation of initial trust. Koufaris et al. (2004) believe that it is a difficult, expensive and time-consuming process for merchants to build a good reputation, so merchants will not do unfair and dishonest behaviors in order to maintain their reputation. Users believe that the higher the reputation of the business will not harm the interests of users, which is the user's trust in the business (Koufaris et al., 2004). At the same time, a good reputation implies that merchants will provide high-quality products or excellent services to enhance users' trust in them (Koufaris et al., 2004). It can be seen that the user's perception of the merchant's reputation will affect their initial trust. Therefore, $\mathrm{H}_{2}$ is proposed in this study.

$\mathrm{H}_{2}$ : Merchant's reputation has a significant positive impact on initial trust of users.

\subsubsection{Personal Trust Tendency}

Whether users are willing to trust other individuals reflects their trust tendency. Users with high trust tendency are often willing to trust others (Green, Karahanna, \& Straub, 2003). When users are unfamiliar with other individuals, trust tendency plays a strong role in the formation of initial trust. With the improvement of familiarity, the importance of trust tendency gradually decreases (Mayer, Davis, \& Schoorman, 1995). Lu et al. (2005) also found that as community members get familiar with the community environment and other community members, the influence of trust tendency on initial trust of members is weakened. Therefore, the higher the propensity of users to trust in transactional virtual communities, the more positive it will be to the establishment of initial trust. As a result, hypothesis $\mathrm{H}_{3}$ is proposed in this study.

$\mathrm{H}_{3}$ : User's personal trust tendency has a significant positive effect on initial trust of users.

\subsection{Initial Trust and Continuous Trust of Users}

Initial trust and continuous trust in transactional virtual communities are two stages in the development of network trust, which reflect the dynamic evolution of trust from formation to stability. In the process of evolution, as virtual community users become more familiar with websites, merchants and other community members, and the volume of transactions increases, the influencing factors and intensity of trust also change. Chen et al. (2008) pointed out in the absence of online shopping experience, users judge whether they trust merchants based on 
their perception of the website's usefulness, usability and reputation. In addition, users with online shopping experience will be more affected by interaction factors, such as whether merchants could timely, quickly and effectively respond to users' needs and how to deal with the relationship between users, which is related to the continuous trust of users. Lu et al. (2005) found that the initial trust of users in virtual communities would encourage users to dilute the virtuality of the network, reduce their concerns about personal information and privacy, and actively communicate and interact with community members and businesses. All the above studies show that continuous trust is based on the initial trust formed by users. Therefore, hypothesis $\mathrm{H}_{4}$ is proposed.

$\mathrm{H}_{4}$ : Initial trust of users has a significant positive effect on continuous trust of users.

\subsection{The Mediating Effect of the Characteristics of Internet Word-Of-Mouth}

As the carrier of Internet word of mouth (WOM), transactional virtual community has its characteristics of community atmosphere, community reliability and online connection strength, which influence users' adoption of transaction information and trust in the community. Price and Feick (1984) and Mannarini, Rochire and Talo (2012) all pointed out that it is easier to exchange product information between users with high homoyopy, because word of mouth is more persuasive when it comes from users similar to themselves. Brown et al. (2007), Bowman et al. (2013) and Ren (2012) et al. shows that members with common group interests and similar minds in the community have high homotopy, people are more likely to believe the information conveyed by homotopy users, and word-of-mouth has a more significant communication effect among highly homotopy individuals. Based on previous studies, Guo and Chen (2009) applied homogeneity to the virtual community environment, proposed the characteristics of community atmosphere, and described the degree to which the information content and interface settings of transactional virtual community are consistent with users' needs, as well as the degree to which users' interests and hobbies and values are consistent with those of other members of the community. As a platform for trading information dissemination and exchange, the reliability of transactional virtual communities affects the attitude and behavior of users, including professionalism and credibility. Professionalism refers to the ability of word-of-mouth communicators to release real information and organize topic discussions, and credibility refers to their willingness to provide objective information (Zhang, 2013). Koh and Kim (2003) show that the professionalism of word of mouth communicators is a key factor affecting trust. Brown et al. (2007) confirmed that virtual community is the node connecting the spreader and receiver of word of mouth in the network environment, and its reliability determines the credibility of product content information and user comments in the community. The strength of online connection reflects the user's familiarity with the community, which is the user's psychological perception of the close relationship with the community and its members. Frenzen and Nakamoto (1993) have proved that when the online connection is high, users believe with high trust that the information received from the word of mouth information spreader is authentic and reliable. Voyer (2000) found that when the online connection of community members is high, members are willing to convey their real opinions and feelings. In this case, users will think that the word-of-mouth information is highly credible and the community is trustworthy. Therefore, hypothesis $\mathrm{H}_{5}$ is proposed in this study.

$\mathrm{H}_{5}$ : The characteristics of Internet word of mouth have significant mediation effect on initial trust and continuous trust of users.

Based on the above literature review and hypotheses, this study proposes that users' perception of websites, merchants' reputation and user's personal trust tendency in transactional virtual communities are independent variables, initial trust of user is an intermediate variable, and the characteristics of internet word of mouth in communities is mediator variable and continuous trust of user in the community is the dependent variable, and then the research model is constructed in Figure 1.

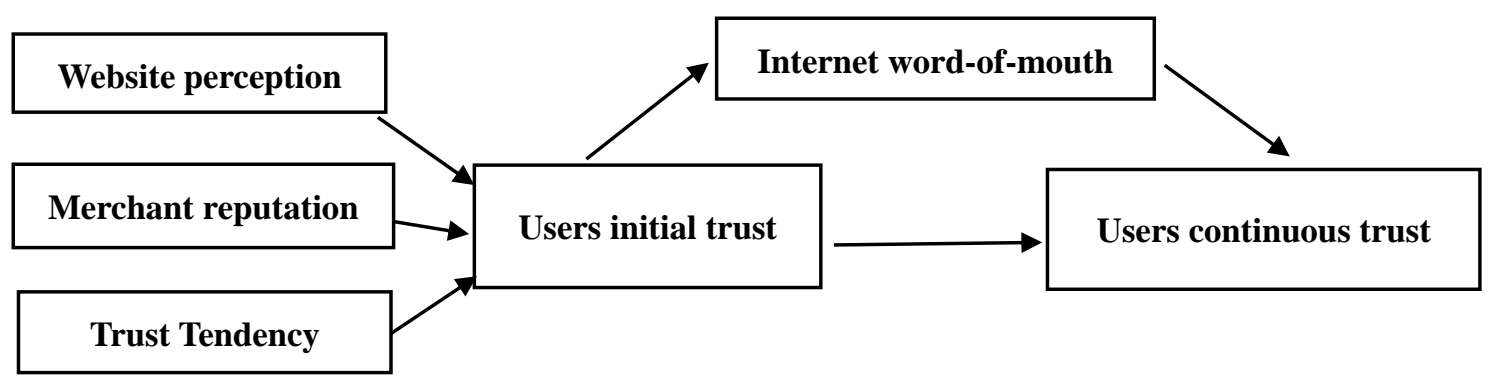

Figure 1. Conceptual Framework 


\section{Research Methodology}

\subsection{Measurement}

In order to ensure the reliability and validity of the scale, this study referred to the maturity scale of existing studies, and slightly modified the maturity scale according to the characteristics of transactional virtual community and Chinese cultural context (Table 1). For the measurement of website perception, this study draws on the research of Gefen et al. (2003) and Koufaris et al. (2004), and carries out the measurement from three aspects of perceived usefulness, perceived ease of use and perceived security, with a total of 8 items. For the measurement of merchant reputation, this study uses Koufaris et al. (2004)'s scale to measure users' perception of merchant reputation. There are 3 items in total. For the measurement of users' trust tendency, referring to Koufaris et al. (2004), there are 3 items in total as well. According to Koufaris et al. (2004), the measurement of initial trust of users consists of four items, including that users believe the information provided by the community, the community will give priority to the interests of users and fulfill their commitments, and consider that the community is reliable. As for the measurement of community internet word of mouth, this study draws on the research of Voyer (2000) and Guo et al. (2009), and measures from the characteristics of community atmosphere, community reliability and online connection strength, with a total of 4 items. Based on the research of Mayer et al. (1995) and Chen et al. (2008), 8 questions were used to measure the continuous trust of users, including ability trust, integrity trust and goodwill trust.

Table 1. Measurement Items and Sources of Questionnaire

\begin{tabular}{|c|c|c|}
\hline Variable & Measurement Item & Source \\
\hline $\begin{array}{l}\text { Website } \\
\text { Perception }\end{array}$ & $\begin{array}{l}\text { Learning to use this community website is easy for me } \\
\text { It's easy to find what I need on this community website } \\
\text { It is not difficult for me to be proficient in using the various functions of the community } \\
\text { website } \\
\text { Using this community website could save me more time } \\
\text { This community website allows me to get the information I need faster } \\
\text { The community website has taken security measures to protect personal information } \\
\text { The community website can verify personal information } \\
\text { The community website can ensure the safety of online transactions }\end{array}$ & $\begin{array}{l}\text { Gefen et al. } \\
\text { (2003) \& } \\
\text { Koufaris et al. } \\
\quad(2004)\end{array}$ \\
\hline $\begin{array}{l}\text { Merchant } \\
\text { Perception of } \\
\text { Reputation }\end{array}$ & $\begin{array}{l}\text { I think the reputation of businesses in this community is better } \\
\text { Products or services provided by businesses in this community are consistent } \\
\text { Businesses in this community care about the needs of consumers }\end{array}$ & $\begin{array}{c}\text { Koufaris et al. } \\
\text { (2004) }\end{array}$ \\
\hline $\begin{array}{l}\text { User Trust } \\
\text { Tendency }\end{array}$ & $\begin{array}{l}\text { Generally speaking, I usually trust others } \\
\text { I believe that human nature is kind } \\
\text { I trust others easily }\end{array}$ & $\begin{array}{c}\text { Koufaris et al. } \\
\text { (2004) }\end{array}$ \\
\hline $\begin{array}{l}\text { User Initial } \\
\text { Trust }\end{array}$ & $\begin{array}{l}\text { I think the community is reliable } \\
\text { I believe that the community gives priority to the interests of community members } \\
\text { I believe the community will fulfill its promise to community members } \\
\text { I believe the information provided by the community }\end{array}$ & $\begin{array}{l}\text { Koufaris et al. } \\
\text { (2004) }\end{array}$ \\
\hline $\begin{array}{l}\text { Internet Word } \\
\text { of Mouth } \\
\text { Characteristics }\end{array}$ & $\begin{array}{l}\text { The atmosphere of the community suits my personality } \\
\text { The content of this community fits my needs very well } \\
\text { I think the community is professional } \\
\text { I believe the information in this community is true and reliable }\end{array}$ & $\begin{array}{l}\text { Voyer (2000) } \\
\text { \& Guo et al. } \\
\quad(2009)\end{array}$ \\
\hline $\begin{array}{c}\text { Continuous } \\
\text { User Trust }\end{array}$ & $\begin{array}{l}\text { The products or services provided by the community are of high quality } \\
\text { The community has the ability and resources to provide high-quality products and services } \\
\text { The community is competitive among similar communities } \\
\text { The promise of the community is reliable } \\
\text { The community treats users honestly } \\
\text { It recommended that the community is based on the best judgment to make the } \\
\text { The intentions of the community are well-intentioned } \\
\text { The community takes the interests of users at heart }\end{array}$ & $\begin{array}{l}\text { Mayer et al. } \\
\text { (1995) \& } \\
\text { Chen et al. } \\
\text { (2008) }\end{array}$ \\
\hline
\end{tabular}




\subsection{Research Design}

This research is a quantitative design using questionnaire to collect data from Chinese users of the well-known transactional virtual communities as research population, such as JD community, Dianping community, Tmall community, Xiaomi Forum, Dangdang - online reading community, etc. The sample size was calculated using Cochran's formula at a confidence level and error term of $95 \%$ and $5 \%$, respectively (Cochran, 1977). The sample size was 385 after calculating.

\subsection{Data Collection}

A web-based online survey was used to collect the data through sharing links to various social platforms and snowballing. First of all, a pilot testing was conducted on 50 members of these communities and the questionnaire was modified according to the reliability and validity test obtained from their suggestions and pretest data. On this basis, a large-scale questionnaire survey was conducted for those Chinese users with transactional virtual community experience. A total of 544 questionnaires were collected, and 390 valid questionnaires were deemed usable after invalid questionnaires were eliminated.

\section{Findings and Analysis}

\subsection{Reliability and Validity Analysis}

This study used Cronbach's alpha coefficient test the reliability of questionnaire. After testing 390 samples, Cronbach's alpha of every factor is greater than 0.7 (Nunnally \& Bernstein, 1994). As a result, the data is reliable in the study. The result is shown in Table 2.

Table 2. Reliability and Validity Analysis

\begin{tabular}{cc}
\hline Variables & Cronbach's Alpha \\
\hline Website Perception & .826 \\
Merchant Reputation & .752 \\
Personal Trust Tendency & .810 \\
Initial Trust of Users & .823 \\
The characteristics of Internet WOM & .889 \\
Continuous Trust of Users & .894 \\
All Scale Factor (30 Items) & .868 \\
\hline
\end{tabular}

In terms of validity test, this research refers to the previous research results, according to the characteristics of transactional virtual communities, which can ensure better content validity. In KMO test and Bartlett sphere test, overall KMO value of 0.909 . For all item do exploratory factor analysis, after 3 times of maximum variance factor rotation, we figure out the 7 principal components, removing an item with factor loading value is less than 0.5 and an item with a higher load on two principal components, finally get the stability of 37 item scale, ensure the difference between validity of the scale. The commonality of all factors ranged from 0.536 to 0.780 , so the validity of this scale was acceptable.

\subsection{Descriptive Analysis}

The detailed demographic profile of the respondents was shown in Table 3. The majority of the respondents was females, relatively young (18-25 years old) students with bachelor degree and has low levels of income. Most of them are users of Tmall community.

Table 3. Demographic Profile of the Respondents

\begin{tabular}{ccc}
\hline Variable & Frequency & $\%(\mathrm{n}=390)$ \\
\hline Gender & & $32.05 \%$ \\
Male & 125 & $67.95 \%$ \\
Female & 265 & $3.08 \%$ \\
Age (years old) & & $82.82 \%$ \\
Under 18 & 12 & $8.21 \%$ \\
$18-25$ & 323 & $2.82 \%$ \\
$26-30$ & 32 & $1.28 \%$ \\
$31-35$ & 11 & $1.79 \%$ \\
$36-40$ & 5 & 7 \\
40 and Over
\end{tabular}




\begin{tabular}{ccc}
\hline Your Education & 32 & $8.21 \%$ \\
High school or below Degree & 33 & $8.46 \%$ \\
Diploma & 246 & $63.08 \%$ \\
Bachelor's Degree & 76 & $19.49 \%$ \\
Master's Degree & 3 & $0.77 \%$ \\
Doctoral Degree & & $46.15 \%$ \\
Monthly Income & 180 & $34.61 \%$ \\
Below 1,000 RMB & 135 & $15.13 \%$ \\
$1,000-2,999$ RMB & 59 & $4.10 \%$ \\
$3,000-5,999$ RMB & 16 & $73.85 \%$ \\
6000 RMB and Above & & $26.15 \%$ \\
Your Occupation & 288 & $11.54 \%$ \\
Student & 102 & $14.87 \%$ \\
Others & & $5.90 \%$ \\
Your Community & 45 & $58.21 \%$ \\
JD community & 58 & $1.54 \%$ \\
DianPing community & 23 & $7.95 \%$ \\
Tmall community & 227 & $605 \%$ \\
Xiaomi Forum & 61 & \\
Others & 31 & \\
Dangdang- online reading community & & \\
\hline
\end{tabular}

\subsection{Multiple Regression Analysis}

In order to avoid multicollinearity among factors, this study constructs a multiple regression model of initial trust of users. The relationship between website perception, merchant reputation, user's personal trust tendency and initial trust of users is discussed. The analysis results are shown in Table 4. As Coefficients Table 4 shows, website perception had a significant positive effect on initial trust of users $(\beta=.199, p<.001)$, which means that $\mathrm{H}_{1}$ was fully supported. In line with our hypothesis, merchant reputation was also found to generate a significant effect on initial trust of users $(\beta=.370, \mathrm{p}<.001)$ in a positive way; Thus, $\mathrm{H}_{2}$ was fully supported. Concerning $\mathrm{H}_{3}$, user's personal trust tendency had a significant positive effect on initial trust of users $(\beta=.339, \mathrm{p}<.001)$, which means that $\mathrm{H}_{3}$ also was fully supported.

Table 4. Multiple Regression Analysis of Initial Trust of Users

\begin{tabular}{|c|c|c|c|c|c|}
\hline \multicolumn{6}{|c|}{ Coefficients } \\
\hline \multirow{2}{*}{ Variable } & Unstandardized Coefficients & Standardized Coefficients & \multirow{2}{*}{$\mathrm{t}$} & \multirow{2}{*}{ Sig. } & \multirow{2}{*}{ VIF } \\
\hline & B & Beta & & & \\
\hline (Constant) & .43 & & 2.03 & .000 & \\
\hline Website perception & .38 & .199 & 2.75 & $.000 * * *$ & 1.20 \\
\hline Merchant reputation & .51 & .370 & 2.91 & $.000 * * *$ & 1.12 \\
\hline User's trust tendency & .45 & .339 & 4.39 & $.000 * * *$ & 1.46 \\
\hline
\end{tabular}

Note: Dependent Variable: Initial trust of users, $* \mathrm{P}<0.05 ; * * \mathrm{P}<0.01 ; * * * \mathrm{P}<0.001$ (2-tailed)

\subsection{Mediation Effect Testing}

This study used the mediation effect test procedure from Wen and Ye in 2014. First, we centralize all variables and make regression of result variables to independent variables. If the regression coefficient is not significant, there is no mediating effect, so the test should be stopped. In other words, the regression coefficient between the user's continuous trust and the user's initial trust is firstly tested in this study. Secondly, we do the regression of mediating variable to independent variable. If the coefficients of the regression equation are significant, then proceed to the next step. If not significant, Sobel test should be performed. In other words, this study should do the regression of the characteristics of Internet word of mouth to the initial trust of users. Finally, this study does regression analysis of dependent variables to independent variables and mediator variable. If the regression coefficient of the mediator variable is not significant, Sobel test should be performed. If the regression coefficient of the mediator variable is significant, it indicates that the influence of the independent variable on the dependent variable is at least partially realized through the mediator variable. If the regression coefficient of 
independent variable is not significant, it is a complete mediator effect, indicating that the influence of independent variable on the dependent variable is completely realized through mediator variable. If the regression coefficient of the independent variable is significant, it is a partial mediator effect, indicating that the influence of the independent variable on the dependent variable is partially realized through the mediator variable. (Wen et al., 2014). In other words, in this study, the regression analysis of continuous trust on initial trust and social Internet word of mouth should be carried out respectively.

The mediation effect test results are shown in Table 5. The second column is the regression analysis result of independent variables (initial trust of users) and dependent variable (continuous trust of users). The regression coefficient is significant $(\mathrm{p}<0.001)$, that is, the initial trust of users has a significant positive impact on the continuous trust of users. Thus, $\mathrm{H}_{4}$ is supported, and it can be tested in the next step. The third column is listed as independent variables (initial trust of users) and mediator variable (Internet word of mouth). The regression coefficient is significant, so the mediation effect analysis could be continuing. Columns 4 and 5 are regression analysis of independent variables (initial trust of users), mediating variables (characteristics of Internet word of mouth) and dependent variables (continuous trust of users), respectively. It can be seen from the results that the regression coefficient of internet word of mouth and the initial trust of users is significant, indicating that the internet word of mouth plays a partial mediating role in the influence of the initial trust of users on the continuous trust of users, and $\mathrm{H}_{5}$ is supported. The ratio of the mediation effect to the total effect was 0.417 $(0.537 \times 0.433 / 0.557)$, that means $41.7 \%$ of the influence of the initial trust on the continuous trust was due to the internet word-of-mouth.

In conclusion, based on the above analysis, the results of hypothesis testing are summarized as shown in Table 6 .

Table 5. Mediation Effect Test

\begin{tabular}{|c|c|c|c|c|}
\hline Variable & $\begin{array}{l}\text { Mediator } \\
\text { variable is not } \\
\text { considered }\end{array}$ & $\begin{array}{l}\text { The relationship between } \\
\text { independent variables and } \\
\text { intermediary variables }\end{array}$ & $\begin{array}{l}\text { The relationship between } \\
\text { the mediator variable and } \\
\text { the dependent variable }\end{array}$ & $\begin{array}{l}\text { Mediator } \\
\text { variable is } \\
\text { considered }\end{array}$ \\
\hline Initial trust of users & $0557 * * *$ & $0.537 * * *$ & & \\
\hline Internet word of mouth & & & $0.433 * * *$ & $0.325^{* * *}$ \\
\hline
\end{tabular}

Table 6. Result of Hypothesis Testing

\begin{tabular}{clc}
\hline Hypotheses & Statement & Result \\
\hline $\mathrm{H}_{1}$ & Website perception has a significant positive impact on initial trust of users. & Supported \\
$\mathrm{H}_{2}$ & Merchant reputation has a significant positive impact on initial trust of users. & Supported \\
$\mathrm{H}_{3}$ & User's personal trust tendency has a significant positive effect on initial trust of users. & Supported \\
$\mathrm{H}_{4}$ & Initial trust of users has a significant positive effect on continuous trust of users. & Supported \\
$\mathrm{H}_{5}$ & The characteristics of Internet word of mouth have significant mediation effect on initial trust & Supported \\
& and continuous trust of users. & \\
\hline
\end{tabular}

\section{Discussion and Conclusions}

Trust is not only the basis of maintaining relationships, but also the premise of attracting new users and building user loyalty. In the context of the Internet, the virtuality and anonymity of the network increase the risk of user transactions, which will be reduced if the trust of users could be gained. In this research, the dynamic process of trust establishment is studied by taking the users of merchant transaction virtual community in the network environment as the research samples. From the result, we know that website perception has a significant positive impact on initial trust of users. This finding is in line with prior study which suggests that web site appeal is found to be a significant predictor of initial trust (Hampton-Sosa \& Koufaris, 2005). Besides, in this study, it is also found that merchant reputation has a significant positive effect on initial trust of users, which is supporting the result of Chen and Barnes (2007) that perceived good reputation of the company is positively related to online initial trust in e-commerce. Furthermore, users' own trust tendency this factor could positively influence the formation of initial trust as well. From the result, we could find that when users first come into contact with the transaction virtual community, if they perceive that the community website is more safe, useful and easy to use, the higher the reputation of merchants in the community and the more inclined they are to trust others, the easier it will be for them to establish initial trust in the community and show more transaction behaviors.

Prior research proposes that initial trust of users in virtual communities encourage users to dilute the virtuality of 
the network, reduce their concerns about personal information and privacy (Lu et al., 2005), which implies that there is a positive relationship between initial trust and continuous trust of users. Similar to this prior determination, the findings in this study also reveal that initial trust of users has a significant positive effect on continuous trust of users. Additionally, the characteristics of Internet word of mouth play a partial mediation effect on initial trust and continuous trust in this study. The initial trust cannot be completely transferred directly to the continuous trust, and $41.7 \%$ of them are affected by the characteristics of Internet word of mouth. It indicates that the formation of initial trust to continuous trust is not achieved directly, and the character of Internet word of mouth plays a key role in bridging the gap. Yet, in previous studies we did not find the mediation impact of Internet word of mouth on initial trust and continuous trust of users. As a result, it could be considered an early attempt to find out the characteristics of Internet word of mouth have significant mediation effect on initial trust and continuous trust of users in transactional virtual community.

\subsection{Implications}

From the results of this study, the necessity of establishing user trust in the network environment can be enlightened. It points out the process of the formation of trust, and also indicates operators and managers of transactional virtual community that the establishment of continuous trust of users should focus on the power of internet word of mouth, especially the cultivation of users' perception of virtual community, which has certain reference significance for the construction and management of transactional virtual community operators.

Firstly, community website developers should design convenient operate and use interface, and put the product information with the most clicks or comments on the top of the page, to prevent the release of pure advertising information; meanwhile, community managers need to adopt a high security trading system to ensure that users' privacy is not violated; Besides, regular testing of the website is also required to update based on user feedback for a better user experience. In addition, community managers should also strengthen the verification of merchants' qualifications, prohibit merchants with bad reputation from entering the community, and formulate sound trading guidelines while supervising merchants' trading behaviors in the community.

Secondly, managers should purify the community of false information and uncivilized speech, filtering distorted information such as propaganda or false reviews, meanwhile, according to the seriousness of the issue, publishers should get punished, such as silenced, being blacklisted or removed from the community, etc. moreover, these lists also need to be publicized in the community, so that managers can strictly control the source of word of mouth, prevent malicious rumors to affect the community word of mouth behavior, and users can feel the professional community, reliability and authenticity of information transmission. It is conducive to the transformation of initial trust to continuous trust of users with a harmonious community atmosphere and good Internet word of mouth.

Finally, community managers need to plan various activities to promote interaction between users, deepen understanding of each other, and break regional boundaries for users to establish friendship. Additional, community managers should also guide users to post comments and opinions, encourage users to express their feelings about the community and the use of products, reward users who provide valuable information, and cultivate users' sense of belonging. Once users consider themselves as members of the community, their information and opinions will have a certain influence on other members in community, so that users themselves and other members are more willing to participate in various activities of the community, and have a sense of immersion in the community. At this spot, users form a virtual community perception. On this basis, users could independently judge whether the community is trustworthy and whether the product information is true and reliable, and their dependence on online word of mouth will be greatly reduced. When bad comments or malicious rumors are made against the community, users will maintain their trust in the community and consciously screen out the bad word of mouth.

\subsection{Limitations and Recommendations}

This study follows scientific principles in theoretical model construction and empirical research, but there are still some limitations: First, the limitations of sample selection. This study selects Chinese users of well-known transactional virtual communities as the research sample, whether it can represent all transactional virtual communities is still need to be considered. Moreover, transactional virtual communities involve different industries, and the differences between industries are not taken into account. In future studies, these factors can be used as control variables to explore the degree of application and influence of various factors. Finally, this study explores the influencing factors of users' initial trust and the formation path of continuous trust, but whether it covers all the factors affecting the formation and maintenance of user trust remains to be identified and demonstrated in future studies. 


\section{References}

Blanchard, A. L. (2008). Testing a model of sense of virtual community. Computers in Human Behavior, 24, 2107-2123. https://doi.org/10.1016/j.chb.2007.10.002

Blanchard, A. L., Welbourne, J. L., \& Boughton, M. D. (2011). A model of online trust: The mediating role of norms and sense of virtual community. Information Communication and Society, 14(1), 76-106. https://doi.org/10.1080/13691181003739633

Bowman, D., \& Narayandas, D. (2013). Managing customer-initiated contacts with manufacturers: The impact on share of category requirements and word -of -mouth behavior. Journal of Marketing Research, 38(3), 281-297. https://doi.org/10.1509/jmkr.38.3.281.18863

Brown, J., Broderick, A. J., \& Lee, N. (2007). Word of mouth communication within online communities: Conceptualizing the online social network. Journal of interactive marketing, 21(3), 2-20. https://doi.org/10.1002/dir.20082

Chen, M. L., Wang, G. P., \& Deng, S. Y. (2008). Comparison of the formation and mechanism of initial network trust and continuous network trust. Journal of Scientific Research Management, 29(5), 187-195

Chen, Y. H., \& Barnes, S (2007). Initial Trust and Online Buyer Behavior. Journal of Industrial Management \& Data Systems, 107(1), 21-36. https://doi.org/10.1108/02635570710719034

CNNIC. (2020). The 45th Statistical Report on the Development of Internet in China. China Internet Network Information Centre. Retrieved from https://cnnic.com.cn/IDR/ReportDownloads/202008/P020200827549953874912.pdf

Cochran, G. W. (1977). Sampling Techniques (3rd ed.). New York, NY: John Wiley \& Sons.

Cronbach, L. J. (1951). Coefficient alpha and the internal structure of tests. Journal of Psychometrika, 16(3), 297-334. https://doi.org/10.1007/BF02310555

Davis, F. D. (1989). Perceived usefulness, perceived ease of use, and user acceptance of information technology. Journal of Mis Quarterly, 13(3), 319-339. https://doi.org/10.2307/249008

Fan, Y. W., \& Miao, Y. F. (2012). Effect of electronic word-of-mouth on consumer purchase intention: The perspective of gender differences. International journal of electronic business management, 10(3), 175-181.

Frenzen, J., \& Nakamoto, K. (1993). Structure, cooperation, and the flow of market information. Journal of Consumer Research, 20(3), 360-375. https://doi.org/10.1086/209355

Gefen, D., Karahanna, E., \& Straub, D. W. (2003). Inexperience and experience with online stores: The importance of TAM and trust. Journal of IEEE Transactions on Engineering Management, 50(3), $307-321$. https://doi.org/10.1109/TEM.2003.817277

Gefen, D., Karahanna, E., \& Straub, D. W. (2003). Trust and TAM in online shopping: An integrated model. Journal of Mis Quarterly, 27(1), 51-90. https://doi.org/10.2307/30036519

Guo, X. C., \& Chen, B. L. (2009). Empirical research on the influencing factors of online word-of-mouth effect. Journal of Beijing Institute of Technology (Social Sciences), 11(2), 31-35.

Hampton-Sosa, W., \& Koufaris, M. (2005). The Effect of Web Site Perceptions on Initial Trust in the Owner Company. International Journal of Electronic Commerce, 10(1), 55-81. https://doi.org/10.1080/10864415.2005.11043965

Jarvenpaa, S. L., Tractinsky, N., \& Vitable, M. (2000). Consumer trust in an Internet store. Journal of Information Technology and Management, 1(1), 45-71. https://doi.org/10.1023/A:1019104520776

Koh, J., \& Kim, Y. G. (2003). Sense of virtual community: A conceptual framework and empirical validation. $\begin{array}{lllll}\text { International Journal of } & \text { Electronic } & \text { Commerce, } & 8(2), & 75-94 .\end{array}$ https://doi.org/10.1080/10864415.2003.11044295

Koufaris, M., \& Hampton, S. W. (2004). The development of initial trust in an online company by new customers. Journal of Protozoology, 41(3), 377-397. https://doi.org/10.1016/j.im.2003.08.004

Lu, Y. B., \& Zhou, T. (2005). Empirical Analysis of the factors affecting consumers' initial online trust in B2C environment. Nankai Business Review, 8(6), 96-101.

Mannarini, T., Rochira, A., \& Talo, C. (2012). How identification processes and inter community relationships affect sense of community. Journal of community psychology, 40(8), 951-967. 
https://doi.org/10.1002/jcop.21504

Mayer, R. C., Davis, J. H., \& Schoorman, F. D. (1995). An integrative model of organizational trust. Academy of Management Review, 20(20), 709-734. https://doi.org/10.5465/amr.2007.24348410

Mcknight, D. H., Cummings, L. L., \& Chervany, N. L. (2011). Initial trust formation in new organizational relationships. Academy of Management Review, 65(11), 152-156. https://doi.org/10.5465/amr.1998.926622

Nunnally, J. C., \& Bernstein, I. H. (1994). Psychometric theory (3rd ed.). New York: McGraw-Hill.

Price, L. L., \& Feick, L. F. (1984). The role of interpersonal sources in external search: An informational perspective. Journal of Advances in Consumer Research, 11(4), 250-255

Ren, Y., Harper, F. M., \& Drenner, S. (2012). Building member attachment in online communities: Applying theories of group identity and interpersonal bonds. Journal of Mis Quarterly, 36(3), 841-864. https://doi.org/10.2307/41703483

Rousseau, D. M., Sitkin, S. B., \& Burt, R. S. (1998). Introduction to special topic forum: Not so different after all - a cross-discipline view of trust. Academy of Management Review, 23(3), 393-404. https://doi.org/10.5465/amr.1998.926617

Voyer, P. A. (2000). Word-of-mouth processes within a services purchase decision context. Journal of Service Research, 3(2), 166-177. https://doi.org/10.1177/109467050032005

Wen, Z. L., \& Ye, B. J. (2014). Mediating effect analysis: Methods and model development. Advances in Psychological Science, 22(5), 731-745. https://doi.org/10.3724/SP.J.1042.2014.00731

Zhang, Y. L. (2013). The impacts of virtual community's online word-of-mouth on consumer's intention. The 19th International Conference on Industrial Engineering and Engineering Management, 1195-1200. https://doi.org/10.1007/978-3-642-38427-1_126

Zhu, Z. Z., Li, X. D., \& Liang, M. L. (2014). Review and Prospect of the research on virtual community sense. Journal of Foreign Economies and Management, 36(4), 36-46.

\section{Copyrights}

Copyright for this article is retained by the author(s), with first publication rights granted to the journal.

This is an open-access article distributed under the terms and conditions of the Creative Commons Attribution license (http://creativecommons.org/licenses/by/4.0/). 